\title{
Natural gas hydrate formation using saline/seawater for gas storage application
}

\author{
Hari Prakash Veluswamy ${ }^{1,2^{*}}$ and Praveen Linga ${ }^{1 *}$ \\ ${ }^{1}$ Department of Chemical and Biomolecular Engineering, National University of Singapore, \\ Singapore 117 585, Singapore \\ ${ }^{2}$ Department of Chemical Engineering, Indian Institute of Technology Roorkee, \\ Roorkee 247667, India
}


Table S1. Singapore seawater composition analysis (Total salinity: $2.72 \mathrm{wt} \%$ )

\begin{tabular}{|l|l|}
\hline Component & Concentration (mg/L) \\
\hline Sodium & 9910 \\
\hline Sulphate & 2520 \\
\hline Potassium & 336 \\
\hline Chloride & 18700 \\
\hline Bromide & 58.8 \\
\hline Fluoride & 2.10 \\
\hline Magnesium & 1200 \\
\hline Calcium & 404 \\
\hline Aluminium & 0.2 \\
\hline Boron & 4.12 \\
\hline Strontium & 9.78 \\
\hline Vanadium & 4.40 \\
\hline Phosphate & 0.12 \\
\hline Lead & $<0.01$ \\
\hline Nickel & $<0.02$ \\
\hline Silver & $<0.02$ \\
\hline Zinc & $<0.02$ \\
\hline Iron & 0.05 \\
\hline Copper & $<0.02$ \\
\hline Nitrite & 0.10 \\
\hline Nitrate & 0.12 \\
\hline Silicon & 0.52 \\
\hline
\end{tabular}




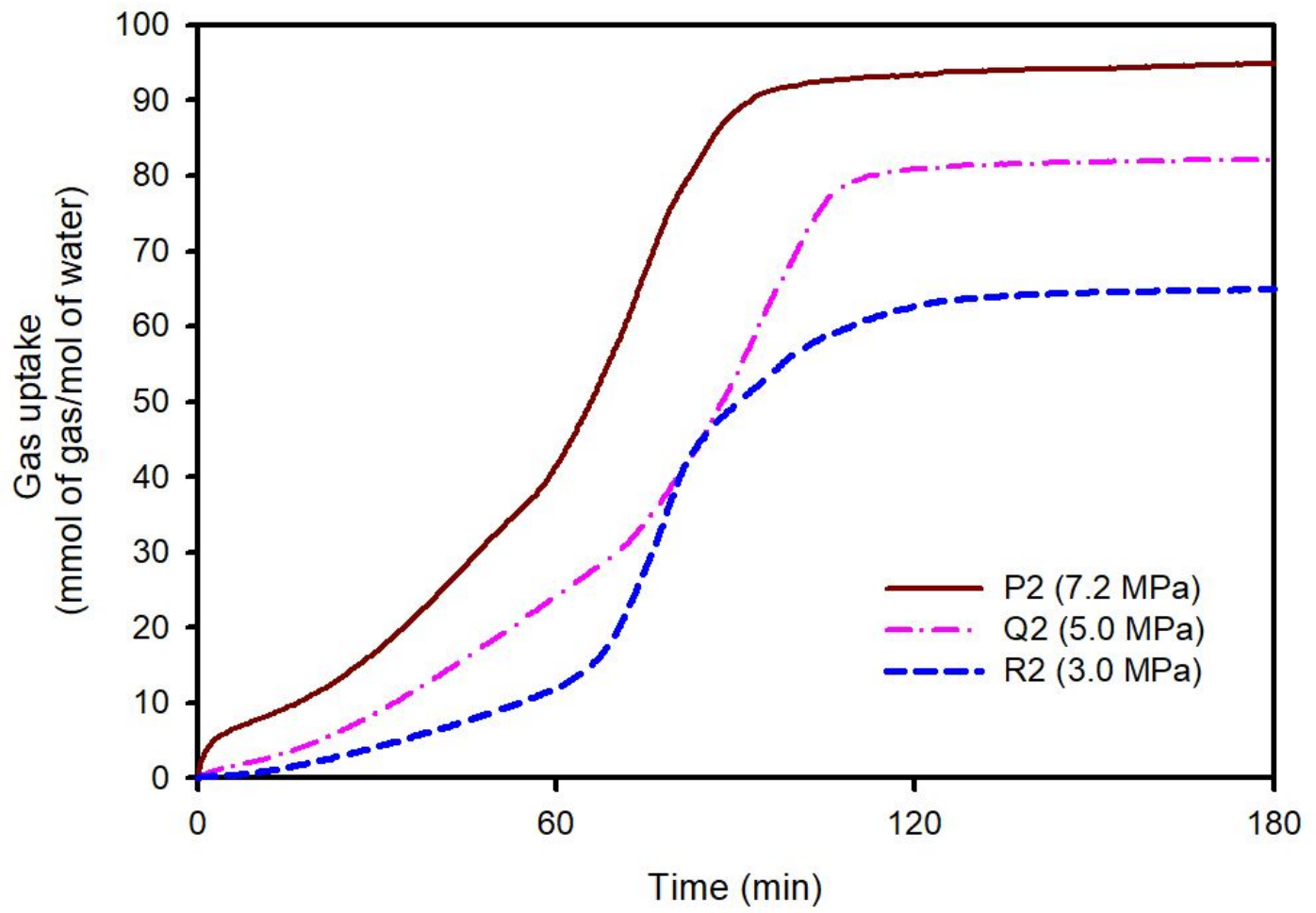

Figure A1. Gas uptake profiles during memory trials of mixed natural gas hydrate formation at different experimental pressures and $283.2 \mathrm{~K}$. 


\section{Procedure for identification of different stages in hydrate growth during mixed natural gas hydrate formation}

Identification of different stages of hydrate growth is by detecting the characteristic slope changes in the gas uptake profiles, as shown in Figure A2. For the Trial R1 (at 3.0 MPa and $283.2 \mathrm{~K}$ ), the first characteristic slope change occurs at $130 \mathrm{~min}$. So, this was identified as the point of transition from stage 1 to stage 2. Similarly, for the trial P1 (at 7.2 MPa pressure and $283.2 \mathrm{~K}$ ), the distinct slope changes occur at $25 \mathrm{~min}$ and $55 \mathrm{~min}$. These points are identified as transition points indicating the start of stage 2 and stage 3 respectively. Minor changes in (predominantly occurring at the start of nucleation) may be ignored if slope change is not significant.

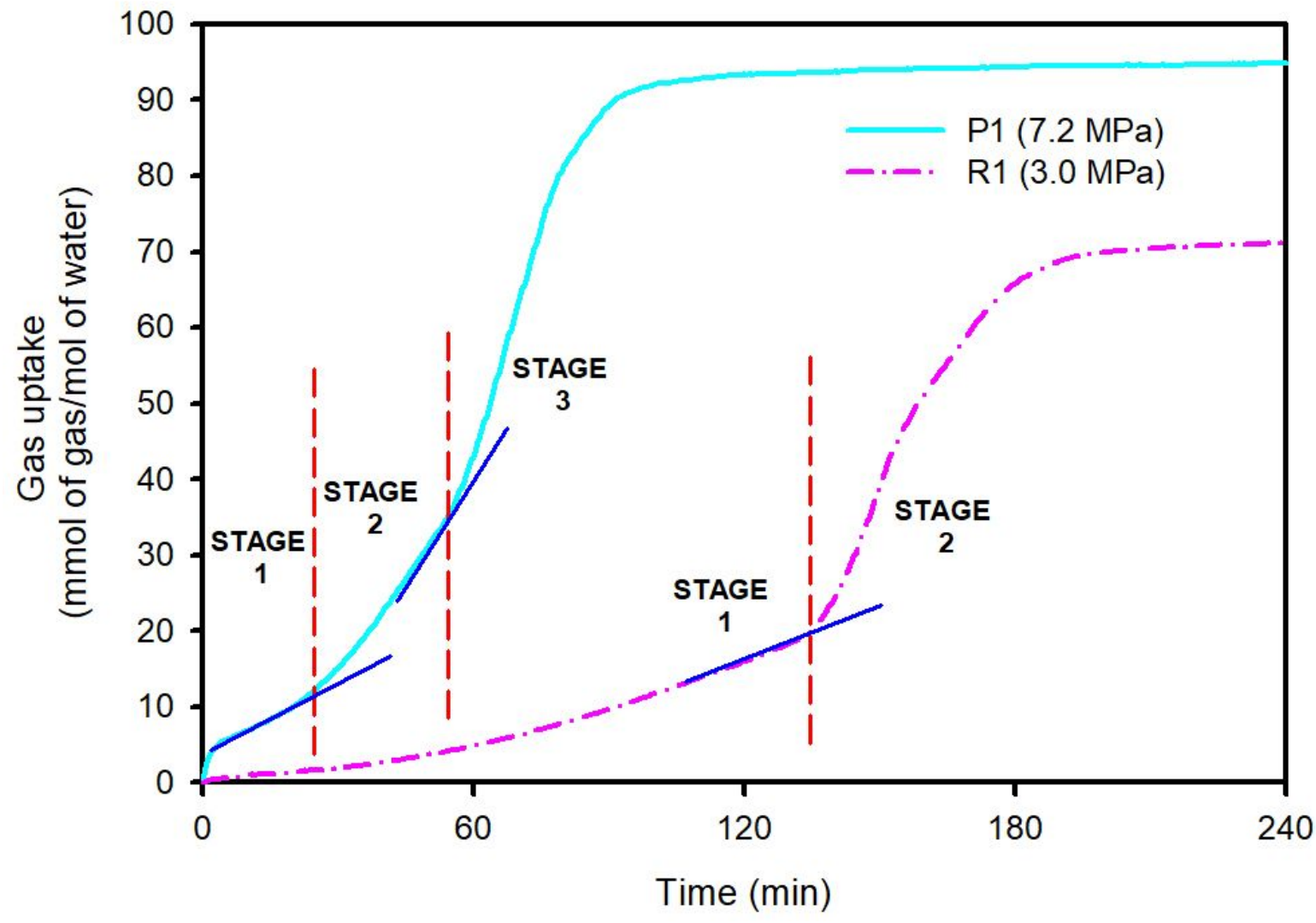

Figure A2. Gas uptake profiles along with slope changes and indication of different stages during selected trials of mixed natural gas hydrate formation at $283.2 \mathrm{~K}$. 